\title{
Impacts of prenatal diagnosis of congenital heart diseases on outcomes
}

\author{
Damien Bonnet ${ }^{1,2}$ \\ ${ }^{1}$ M3C-Necker, Hôpital universitaire Necker-Enfants malades, Assistance Publique-Hôpitaux de Paris, Paris, France; ${ }^{2}$ Université de Paris, Paris, \\ France \\ Correspondence to: Pr Damien Bonnet, MD, PhD. M3C-Necker, Congenital and pediatric cardiology department, Necker-Enfants malades Hospital, \\ Assistance Publique-Hôpitaux de Paris, 149, rue de Sèvres 75015 Paris, France. Email: damien.bonnet1@gmail.com.
}

\begin{abstract}
Prenatal diagnosis of congenital heart diseases (CHD) is increasingly performed in developed countries. Still, the current impacts of prenatal diagnosis on fetal and neonatal outcomes remains unclear or contradictory. We will review here the different consequences of prenatal screening and of fetal echocardiography on different categories of outcomes. Increasing detection may lead to a reduced birth incidence of severe complex CHD through a high rate of termination of pregnancy but this trend is not universal. Conversely, one of the main impacts of prenatal diagnosis is to optimize perinatal care and to improve hard outcomes such as mortality. Indeed, decrease of neonatal mortality is inconsistently observed in transposition of the great arteries and is not shown in other defects. The reduction of perinatal morbidity is a new end-point to scrutinize but how to examine this impact is controversial in the neonatal period. The influence of the reduction of neonatal distress may modify neurodevelopmental outcomes and quality of survival. The risk stratification after a prenatal diagnosis of CHD helps to optimize the timing, mode, and site of management with the aim to improve outcomes. The anticipated care is tailored according to the type of CHD and expected initial physiology. However, the imprecision of prenatal diagnosis even in expert centers hampers this logical outcome. Prediction of the type of repair is theoretically possible but remains challenging in defects such as double outlet right ventricles or pulmonary atresia with ventricular septal defect. The cost of prenatal diagnosis or of its absence is still a matter of debate and policies have to be tailored to regional health systems. Finally, the impact on parents and siblings is a rarely explored outcome. Screening and echography of fetal heart are currently performed in developed countries but it is still too early to talk about fetal cardiology.
\end{abstract}

Keywords: Prenatal diagnosis; fetus; cost-effectiveness; mortality; morbidity

Submitted Aug 26, 2020. Accepted for publication Oct 21, 2020.

doi: $10.21037 /$ tp-20-267

View this article at: http://dx.doi.org/10.21037/tp-20-267

\section{Introduction}

The consequences of prenatal ultrasound screening for the detection of congenital heart diseases (CHD) are multiple $(1,2)$. It is now currently offered to the majority of pregnant women in developed countries although the prenatal screening policies and detection rates vary significantly. The first impact for severe CHD, and the most intuitive for the parents, is the interrogation on the outcome of the pregnancy. Indeed, the diagnosis of a CHD raises the question to terminate or to continue the pregnancy, and this decision will depend on a variety of factors (3-5). We will discuss briefly these determinants of termination of pregnancy after prenatal diagnosis of a CHD.

Prenatal diagnosis may also improve treatment success by allowing appropriate organization of neonatal care. The first potential impact is reduction of neonatal mortality. Since this issue had been demonstrated in transposition of the great arteries, it has been widely claimed that prenatal diagnosis was key to organize delivery in an appropriate 
center to prevent neonatal demise in critical defects (6-8). Today, this issue is a matter of debate without questioning the importance of fetal detection of CHDs.

The prenatal diagnosis of the majority of CHD has logically no significant impact on neonatal mortality because the anticipated physiology of the defect will not lead to neonatal demise (9). If mortality is not a pertinent end-point, morbidity is certainly an important outcome to scrutinize after prenatal diagnosis of CHD $(10,11)$. Still, there are different types of morbidity, namely neonatal and late aftermaths. Further, the prevention of these morbidities can take different routes: in utero interventions, optimization of cardiac diagnosis, tailored post-natal management. We will examine these different issues in the present review.

\section{Prenatal diagnosis of CHD and termination of pregnancy: the impossible debate}

When should termination of pregnancy be proposed after prenatal diagnosis of a CHD is hardly debatable in a review manuscript as the considerations vary largely from a country to another with regards to the legal and cultural environments of this issue (4). A combination of maternal and fetal factors will contribute to the decision to pursue or not the pregnancy. In addition, specific features of the CHD and potential associated anomalies will also have a direct impact on this decision-making process $(12,13)$. The influence of prenatal diagnosis on the incidence of severe CHD is certain in many European countries $(4,5)$. As an example, in the Paris registry, the proportion of termination of pregnancy for single ventricle was $63 \%$ in the late 1990s (5). A recent report from Norway also attests to care practices closely linked to the behavior and philosophical education of the population. The authors report a mortality of complex CHD—all surgical defects including large VSD—of $10 \%$, with palliative care and termination of pregnancy accounting for $86 \%$ of the cases (14). This high proportion of termination of pregnancy led to a reduction of perinatal mortality as about one quarter of early neonatal deaths are due to congenital anomalies, and of these $25 \%$ are CHD in the EUROCAT registry regions (4). Qualifying this impact positive or negative is a philosophical issue. Another limitation for the interpretation of the impact of prenatal diagnosis of $\mathrm{CHD}$ on perinatal outcomes is the proportion of CHD that are diagnosed compared to the live birth incidence. If $100 \%$ of hypoplastic left heart syndromes are diagnosed prenatally and $50 \%$ of parents choose termination of pregnancy, the perinatal mortality-including fetal and neonatal-will be at least $50 \%$, but if only $20 \%$ of hypoplastic left heart syndromes are detected prenatally and $100 \%$ are terminated, the perinatal mortality will be reduced! Reporting the impact of prenatal diagnosis of $\mathrm{CHD}$ as a whole or of specific CHDs will largely depend on the proportion of prenatal diagnosis, but also on treatment success in the concerned area. More, interpreting data that are not population-based for this purpose is largely inaccurate. Finally, detecting congenital anomalies can be considered a side-effect of a general policy of mother and fetal monitoring. The primary objective is definitely to detect any threat for the well-being of the fetus or of the mother and to organize delivery in optimal conditions. This approach would suggest that the only useful objectives of examining the fetal heart is diagnosing anomalies that can be improved by early treatment (i.e., fetal tachyarrhythmias) or modification of the delivery conditions. Considering this approach-another philosophical issue-, the whole debate on when are karyotyping or extensive screening for extracardiac malformations indicated is vain as it will not lead to fetal treatment or to change of delivery conditions. Conversely, a majority of physicians involved in fetal CHD management will consider that $\mathrm{CHD}$ can be associated with chromosomal anomalies and extracardiac anomalies, and will propose to search for these associations to optimize perinatal organization.

Of course, the association of a CHD with a high risk of neurodevelopmental delay due to a chromosomal anomaly will strongly influence the decision to terminate the pregnancy for some parents (15). However, this information might be of limited impact in some populations because of moral and/or religious beliefs $(15,16)$. Fetal cardiologists will also influence the decision with their own beliefs. When these issues were debated 30 years ago, this led to combative exchanges by editorialists who did not hesitate to summon Kant in their papers or to humbly suggest that fetal ultrasound has a role in the future of humanity (17-19). For example, outcomes informations influence the decision of termination in univentricular hearts, i.e., dominant left ventricles are less terminated than dominant right ventricles while a higher mortality in dominant right ventricle has not been clearly shown in postnatal studies except for hypoplastic left heart syndrome $(19,20)$. Corno elegantly discussed the different issues of prenatal diagnosis of univentricular hearts and the complexity of adequately counseling/guiding the parents without limiting their autonomy (21). 


\section{Impact of prenatal diagnosis on neonatal mortality}

Health outcomes are improved when neonates with critical CHDs are detected before acute cardiovascular collapse. Both prenatal ultrasound screening and pulse oximetry are used to identify these babies at risk (22). Even though both of these methods are available in developed countries, their sensitivity remains insufficient and a significant proportion of critical CHDs are diagnosed late. Owing to the lack of accurate screening test that can detect critical CHDs, prenatal diagnosis can help to improve immediate outcomes through a better coordination of care and advanced planning. Nevertheless, there is conflicting data regarding the impact of prenatal diagnosis on early mortality $(2,5,10,23-25)$. Historically, the mortality benefit of prenatal detection of hypoplastic left heart and transposition of the great arteries has been demonstrated in a few tertiary centers series, but these results have not been replicated consistently in population-based series (6,7,23-25). Again, the survival benefit of prenatal diagnosis varies with the type of defect. It is intuitive that neonates with restrictive foramen ovale will be in critical condition rapidly in simple transposition of the great arteries or in hypoplastic left heart syndrome (26). For these patients, the sooner the Rashkind procedure is performed, the better will be the preoperative mortality. The proportion of neonates who will require immediate Rashkind procedure in these two defects is limited and the contribution of these patients to the immediate mortality is predominant. The pragmatic issue here would be to detect these at-risk patients and to tailor advanced care according to prenatal characteristics that predict with a high sensitivity the need for a Rashkind procedure (27). Despite a large number of publications on prenatal anatomical and physiological characteristics of the foramen ovale as well as on prenatal risk scales, the organization of perinatal care largely depends on local considerations and on national health systems $(28,29)$. Li et al. reviewed in a meta-analysis of 13 cohort studies the effect of prenatal diagnosis on mortality and concluded the it was effective in accelerating intervention for major congenital heart disease, but only resulted in a reduced perioperative mortality in cases of transposition of the great arteries (25). The decrease in mortality in the last 20 years in complex CHD may explain why prenatal detection does not improve overall mortality in CHD. This disappointing observation might be related to a combination of the effects of prenatal detection and other factors, including an increased awareness of CHD in the postnatal primary and secondary care setting, awareness of the importance or urgent transfer once a diagnosis is suspected, and improvements in care management before and during transfer (30).

Population-based study are rare and this complicates the interpretation of the existing literature as outcomes from specialized centers may not reflect those in the population of patients as a whole and be subject to transfer and/or survival bias. In addition, the mortality outcomes assessed are often limited to preoperative or short-term postsurgical mortality whereas longer-term mortality such as the overall infantile mortality has been assessed much less frequently (10). Some studies have even observed a worse outcome in neonates diagnosed prenatally $(31,32)$. This disconcerting finding might be due to the fact that more critical varieties of CHD were more easily identified during ultrasound screening. These data imply that at least in the settings where specialized services are readily available, survival may no longer be the most relevant outcome, or the best criterion, for evaluating the impact of prenatal diagnosis on the outcome of CHD. The beneficial effects of prenatal diagnosis may be better sought by looking at morbidity or non-medical outcomes such as costs, social consequences and parental consequences (Figure 1).

\section{Impact of prenatal diagnosis of CHD on morbidity}

The early postnatal course of babies with critical CHD can be negatively impacted if diagnosis is delayed. As for mortality, there is inconsistent evidence to support the fact that prenatal diagnosis results in better perioperative outcomes. It has been demonstrated that prenatal diagnosis of CHD substantially shifts intervention to an earlier period of time for a given CHD (1,33). For transposition of the great arteries or hypoplastic left heart syndrome, early intervention is indicated for the prevention of further cardiac or neurological injuries due to hypoxia and harmful hemodynamics. Despite representing more severe lesions compared to postnatal diagnosis, prenatal diagnosis was associated with decreased use of mechanical ventilation, antibiotics, and emergent surgery (9). An analysis reviewed the Society of Thoracic Surgeons Congenital Heart Surgery Database to assess potential associations between prenatal diagnosis of CHD and the presence of well-defined pre-operative risk factors in patients undergoing cardiac surgery (33). The preoperative risk factors included shock, 


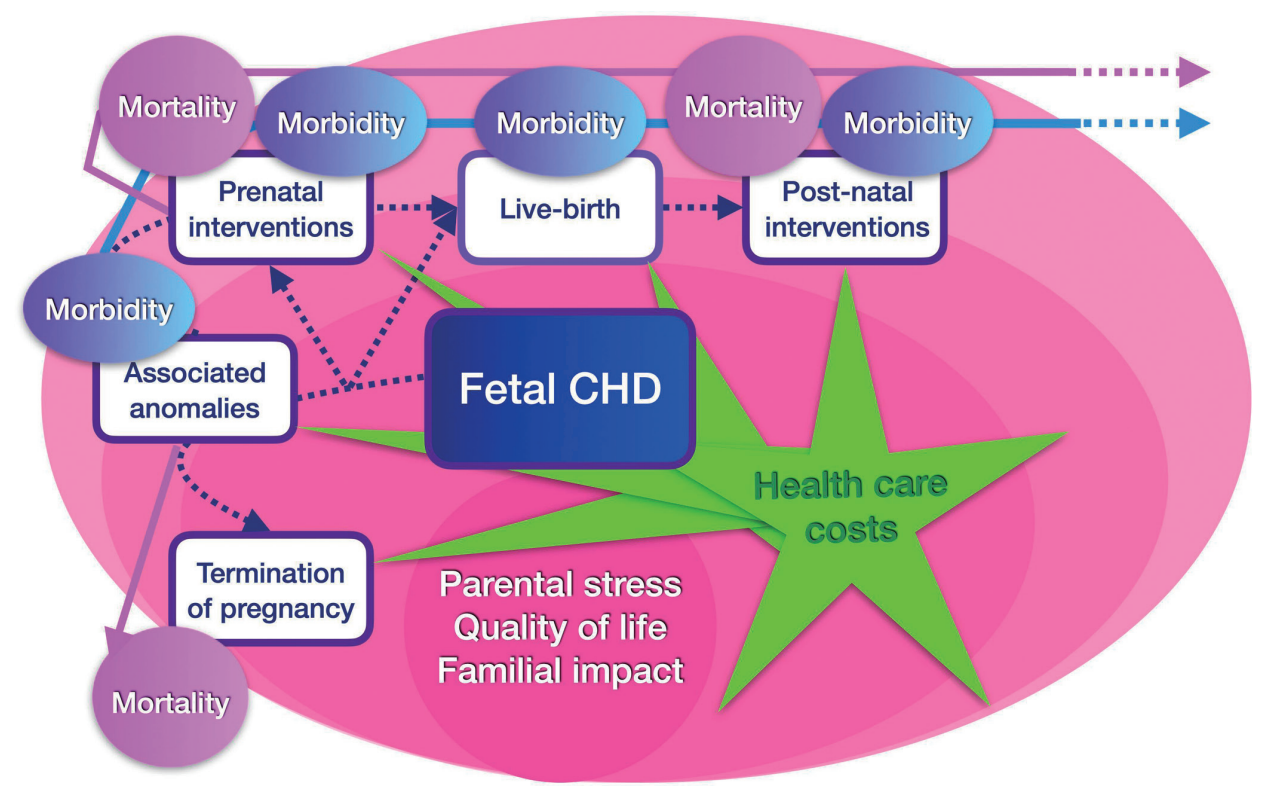

Figure 1 Different impacts of prenatal diagnosis of congenital heart diseases. Practical consequences follow the perinatal organization path with alternate route for the fetus and the parents before and after birth. These technical impacts are permanently associated with the psychological and social consequences of the prenatal diagnosis of the congenital heart disease as well as with the background problematic of cost-effectiveness depending on the local health care system.

mechanical ventilatory and circulatory support, and various organ failures. The authors demonstrated that prenatal diagnosis of critical CHD was associated with lower rates of major pre-operative risk factors. We had previously shown that prenatal diagnosis of transposition of the great arteries was associated with lower occurrence of metabolic acidosis and organ failure (6).

With regards to the risk of premature delivery, contradictory informations have also been given. Landis et al. showed that prenatal diagnosis was associated with increased odds of a scheduled delivery, and birth before a gestational age of 39 weeks (34). In the EPICARD study, Laas et al. found that overall preterm newborns with CHD, particularly those who were born at $<35$ weeks of gestational age, had a substantially higher risk of mortality than those born at term (37-41 weeks), but the same group showed that the higher risk of preterm birth in newborns with CHD, was essentially due to spontaneous labor and not scheduled delivery $(35,36)$. The attempted route of delivery (vaginal or caesarian section) for fetal cardiac anomaly had no impact on neonatal morbidity while prenatal diagnosis reduced the need for invasive respiratory support (37).

Improvement of clinical condition at presentation might have an impact on quality of survival and, in particular, neurological morbidity. Mahle et al. showed that infants with a prenatal diagnosis of hypoplastic left heart syndrome had fewer adverse perioperative neurologic events when directly compared with infants diagnosed postnatally (38). Late neurological outcomes are also improved after prenatal diagnosis of transposition of the great arteries. Calderon et al. showed that neurocognitive deficits were more prevalent and more severe in children with a postnatal diagnosis of this CHD (39). Further, prenatal diagnosis was associated with better outcomes in executive functions in children of 5 years in the same cohort. These early and late outcomes are not surprising, given the severe circulatory collapse that can occur after postnatal ductal or foramen ovale constriction in neonates with these two defects (28). It is highly probable that improvement of preoperative conditions through prenatal diagnosis will improve quality of survival in children with critical CHD, and this starts to be proven in observational studies.

\section{Impact of prenatal diagnosis for management strategies}

The risk stratification after a prenatal diagnosis of CHD will lead to optimize the timing, mode, and site 
of management with the aim to improve outcomes. The anticipated care is tailored according to the type of CHD and expected initial physiology (40). This evaluation of risk shall not be limited to the sole type of CHD but should take into account the variations for a given defect. As an example, the proportion of neonatal interventions after a fetal diagnosis of tetralogy of Fallot is low but this might have different causes: ducto-dependency with almost atretic right outflow tract or disconnected pulmonary artery branches (41). Planning to deliver all tetralogies of Fallot in tertiary centers is probably not recommended but the role of echocardiography is to identify, if possible, the factors that will modify management for each subset of CHD. In daily practice, expertise after prenatal screening for CHD not only leads to a precise diagnosis, but also allows tailored counselling that takes individual prognostic factors into account (42). The optimization of perinatal management will usually be planned by a multidisciplinary team with the role to ensure birth of affected infants into the appropriate level of care. It is important here to introduce humility in this risk stratification approach. Actually, we and others have shown that correcting fetal cardiac diagnosis after birth can lead to significant changes in neonatal and late care strategies (43). Clinicians should therefore be cautious when predicting required treatment and outcomes during pre-natal counseling.

Another important impact of prenatal diagnosis on management is the monitoring of evolutive cardiac anomalies. The most common situation is exaggerated leftright asymmetry of the ventricles and their corresponding concordant vessels during the second trimester of pregnancy that increases the risk for neonatal coarctation. But despite improvements in imaging technology, and sophisticated composite measurements of intracardiac and arch dimensions, derived ratios and Doppler interrogation, the diagnosis of coarctation of the aorta is still a challenging diagnosis to make in utero (44). True false negative cases cannot be clearly identified as this would suppose a systematic comprehensive assessment of cardiac left side dimensions at screening. False positive cases represent a fourth of neonates referred for left-right asymmetry and this suggests to improve the performance of this diagnosis prenatally. Cardiac monitoring is also important to optimize delivery conditions in other evolutive defects such as the Ebstein anomaly, pulmonary atresia with intact ventricular septum or aortic stenosis (45-47).

The final impact on management after a prenatal diagnosis of CHD is to indicate interventions to modify the supposed natural history of some lesions. The development of fetal interventions has somehow accompanied studies on the fetal natural history of evolutive defects. The CHDs for which intervention has been undertaken during fetal life include, critical aortic stenosis, pulmonary atresia, and hypoplastic left heart with intact atrial septum (48-50).

Indicating intervention to avoid the involution of the left ventricle and a neonatal physiology of hypoplastic left heart is still a matter of debate. The stakes are very high here as being wrong may mean the difference between a critically ill infant and a mild anomaly with limited consequences at birth (51). The lack of clear physiologic markers to predict these different outcomes is problematic, and no final guidelines have yet been proposed in this condition.

Neonates with hypoplastic left heart syndrome and atrial level restriction have a particularly poor prognosis (52). This obstruction to left atrial egress leads to arterialization of pulmonary veins, which may persist despite successful opening of the atrial septum and decompression of the left atrium before or after birth (53). The upcoming expansion of fetal cardiac interventions to ameliorate critically progressive fetal lesions intensifies the need to address issues about the adequacy of technological assessment and patient selection as well as the morbidity of those who undergo these procedures. Beside fetal interventions, maternal hyperoxygenation has been proposed to identify fetuses requiring postnatal intervention on the interatrial septum (54). There have also been anecdotal reports that maternal hyperoxygenation may result in growth of the left side of the heart including aortic arch, and studies are currently exploring this interesting issue $(55,56)$. Further, maternal hyperoxygenation may have an impact on brain development in some CHD by resetting the brain perfusion heterogeneity and favoring brain oxygen consumption and growth (57). Today, we are certainly in the preliminary phase of applying new treatment strategies in fetuses with CHD as designing such studies will be extremely complex and we will have to rely on observational and imperfect data to improve our practice.

\section{Impact of prenatal diagnosis of CHD on health care costs}

Cost is usually a neglected outcome in the ecosystem of prenatal screening and fetal echocardiography. It is however of importance as over half of the cost attributed to all birth defects combined is currently associated with the care of CHD in developed countries (58). Prenatal screening and 
expertise of CHD are the first contributors to the costs. But, the impact of prenatal screening of CHD on healthcare costs remains unclear. The health-care costs may decrease if prenatal diagnosis leads to fewer emergent transports and decreases morbidities associated with delayed diagnosis $(6,7,34,59,60)$. Conversely, overall costs could also be augmented because of the supplementary additional prenatal procedures and expenses when previous delivery plans are modified. In utero transportation and competition among centers may change the area of referral. Finally, increased costs can be expected in institutions dealing with a large number of fetal CHD, and funds received by these institutions should be proportional to their needs. These issues should certainly be considered to identify ways in which to deliver care more efficiently.

\section{Impact of prenatal diagnosis of CHD on familial functioning}

The diagnosis of CHD in the fetus places the well-being of the entire family at risk as the burden of care increases vulnerability to major psychological and social disturbances. Immediately after the first announcement of the cardiac malformation, parents report elevated levels of anxiety, depression, and stress. Mental health problems in parents during the prenatal and early childhoods period will impact the emotional, behavioral, and developmental outcomes of affected children and potentially their siblings (61). Thus, appropriate counseling is mandatory to prevent or minimize the psychological consequences of prenatal diagnosis of CHD on parental stress (62). Clinical risk factors for neurodevelopmental impairment in children with CHD have been identified but most are medically necessary and not easily modifiable (63). In the context of prenatal diagnosis of CHD, psychological interventions, practice changes, and community supports may improve parent mental health problems and stress, and, consequently, impact the developmental and behavioral trajectories of these vulnerable children $(15,64)$.

\section{Conclusions}

The common sense would conclude that prenatal diagnosis of CHD is useful in critical CHD such as hypoplastic left heart syndrome, transposition of the great arteries and total anomalous pulmonary venous return as it may accelerate interventions after birth and preserve long- term neurodevelopment. There is however no clear evidence for the benefit of prenatal detection of the vast majority of CHD for the fetus or the "unborn child". Beside morbi-mortality and organization of perinatal care, the positive impact of prenatal diagnosis of CHD is even less obvious, i.e., for cost-effectiveness or parental psychological consequences. Nevertheless, this topic is at the complex frontier between congenital cardiology, health care organization, philosophy and metaphysic. There is no scientific truth in the field. Continuous sharing of clinical experience and interaction between various disciplines is stimulating and will certainly lead to increase knowledge and fruitful innovations in the future.

\section{Acknowledgments}

Funding: None.

\section{Footnote}

Provenance and Peer Review: This article was commissioned by the Guest Editor (Antonio F. Corno) for the series "Prenatal Diagnosis in Congenital Heart Defects" published in Translational Pediatrics. The article has undergone external peer review.

Conflicts of Interest: The author have completed the ICMJE uniform disclosure form (available at http://dx.doi. org/10.21037/tp-20-267). The series "Pre-natal Diagnosis in Congenital Heart Defects" was commissioned by the editorial office without any funding or sponsorship. The authors have no other conflicts of interest to declare.

Ethical Statement: The author are accountable for all aspects of the work in ensuring that questions related to the accuracy or integrity of any part of the work are appropriately investigated and resolved.

Open Access Statement: This is an Open Access article distributed in accordance with the Creative Commons Attribution-NonCommercial-NoDerivs 4.0 International License (CC BY-NC-ND 4.0), which permits the noncommercial replication and distribution of the article with the strict proviso that no changes or edits are made and the original work is properly cited (including links to both the formal publication through the relevant DOI and the license). See: https://creativecommons.org/licenses/by-nc-nd/4.0/. 


\section{References}

1. Cloete E, Bloomfield FH, Sadler L, et al. Antenatal Detection of Treatable Critical Congenital Heart Disease Is Associated with Lower Morbidity and Mortality. J Pediatr 2019;204:66-70.

2. Chakraborty A, Gorla SR, Swaminathan S. Impact of prenatal diagnosis of complex congenital heart disease on neonatal and infant morbidity and mortality. Prenat Diagn 2018;38:958-63.

3. Han B, Li Y, Tang Y, Qu X, et al. Clinical analysis of prenatal ultrasound diagnosis of fetal cardiovascular malformations in the first and second trimesters of pregnancy: A CARE-compliant article. Medicine (Baltimore) 2019;98:e16822.

4. Dolk H, Loane M, Garne E; European Surveillance of Congenital Anomalies (EUROCAT) Working Group. Congenital heart defects in Europe: prevalence and perinatal mortality, 2000 to 2005 . Circulation 2011;123:841-9.

5. Khoshnood B, De Vigan C, Vodovar V, et al. Trends in prenatal diagnosis, pregnancy termination, and perinatal mortality of newborns with congenital heart disease in France, 1983-2000: a population-based evaluation. Pediatrics 2005;115:95-101.

6. Bonnet D, Coltri A, Butera G, et al. Detection of transposition of great arteries in fetuses reduces neonatal morbidity and mortality. Circulation 1999;99:916-8.

7. Tworetzky W, McElhinney DB, Reddy VM, et al. Improved surgical outcome after fetal diagnosis of hypoplastic left heart syndrome. Circulation 2001;103:1269-73.

8. Franklin O, Burch M, Manning N, et al. Prenatal diagnosis of coarctation of aorta improves survival and reduces morbidity. Heart 2002;87:67-9.

9. Levey A, Glickstein JS, Kleinman CS, et al. The impact of prenatal diagnosis of complex congenital heart disease on neonatal outcomes. Pediatr Cardiol 2010;31:587-97.

10. Khoshnood B, Lelong N, Houyel L, et al. Impact of prenatal diagnosis on survival of newborns with four congenital heart defects: a prospective, population-based cohort study in France (the EPICARD Study). BMJ Open 2017;7:e018285.

11. Friedberg MK, Silverman NH, Moon-Grady AJ, et al. Prenatal detection of congenital heart disease. J Pediatr 2009; 155:26-31; 31.e21.

12. Germanakis I, Sifakis S. The impact of fetal echocardiography on the prevalence of liveborn congenital heart disease. Pediatr Cardiol 2006;27:465-72.
13. Quartermain MD, Pasquali SK, Hill KD, et al. Variation in Prenatal Diagnosis of Congenital Heart Disease in Infants. Pediatrics 2015;136:e378-385.

14. Wik G, Jortveit J, Sitras V, Døhlen G, Rønnestad AE, Holmstrøm H. Severe congenital heart defects: incidence, causes and time trends of preoperative mortality in Norway. Arch Dis Child 2020;105:738-43.

15. Arya B, Glickstein JS, Levasseur SM, et al. Parents of children with congenital heart disease prefer more information than cardiologists provide. Congenit Heart Dis 2013;8:78-85.

16. Xie D, Wang H, Liu Z, et al. Perinatal outcomes and congenital heart defect prognosis in 53313 non-selected perinatal infants. PLoS One 2017;12:e0177229.

17. Huhta JC. Uses and abuses of fetal echocardiography: a pediatric cardiologist's view. J Am Coll Cardiol 1986;8:451-8.

18. Squarcia U. Fetal diagnosis of congenital cardiac malformations - a challenge for physicians as well as parents. Cardiol Young 1996;6:256-7.

19. Shinebourne EA, Carvalho JS. Ethics of fetal echocardiography. Cardiol Young 1996;6:261-3.

20. d'Udekem Y, Xu MY, Galati JC, et al. Predictors of survival after single-ventricle palliation: the impact of right ventricular dominance. J Am Coll Cardiol 2012;59:1178-85.

21. Corno AF. "Functionally" univentricular hearts: impact of pre-natal diagnosis. Front Pediatr 2015;3:15.

22. Plana MN, Zamora J, Suresh G, et al. Pulse oximetry screening for critical congenital heart defects. Cochrane Database Syst Rev 2018;3:CD011912.

23. van Velzen CL, Clur SA, Rijlaarsdam ME, et al. Prenatal detection of congenital heart disease--results of a national screening programme. BJOG 2016;123:400-7.

24. Gorla SR, Chakraborty A, Garg A, et al. Emerging trends in the prenatal diagnosis of complex CHD and its influence on infant mortality in this cohort. Cardiol Young 2018;1-7. [Epub ahead of print].

25. Li YF, Zhou KY, Fang J, et al. Efficacy of prenatal diagnosis of major congenital heart disease on perinatal management and perioperative mortality: a meta-analysis. World J Pediatr 2016;12:298-307.

26. Kumar RK, Newburger JW, Gauvreau K, et al. Comparison of outcome when hypoplastic left heart syndrome and transposition of the great arteries are diagnosed prenatally versus when diagnosis of these two conditions is made only postnatally. Am J Cardiol 1999;83:1649-53. 
27. Jouannic JM, Gavard L, Fermont L, et al. Sensitivity and specificity of prenatal features of physiological shunts to predict neonatal clinical status in transposition of the great arteries. Circulation 2004;110:1743-6.

28. Vigneswaran TV, Zidere V, Miller OI, et al. Usefulness of the Prenatal Echocardiogram in Fetuses With Isolated Transposition of the Great Arteries to Predict the Need for Balloon Atrial Septostomy. Am J Cardiol 2017;119:1463-7.

29. Słodki M, Axt-Fliedner R, Zych-Krekora K, et al. New method to predict need for Rashkind procedure in fetuses with dextro-transposition of the great arteries. Ultrasound Obstet Gynecol 2018;51:531-6.

30. Wu W, He J, Shao X. Incidence and mortality trend of congenital heart disease at the global, regional, and national level, 1990-2017. Medicine (Baltimore) 2020;99:e20593.

31. Mazwi ML, Brown DW, Marshall AC, et al. Unplanned reinterventions are associated with postoperative mortality in neonates with critical congenital heart disease. J Thorac Cardiovasc Surg 2013;145:671-7.

32. Wright LK, Ehrlich A, Stauffer N, et al. Relation of prenatal diagnosis with one-year survival rate for infants with congenital heart disease. Am J Cardiol 2014;113:1041-4.

33. Quartermain MD, Hill KD, Goldberg DJ, et al. Prenatal Diagnosis Influences Preoperative Status in Neonates with Congenital Heart Disease: An Analysis of the Society of Thoracic Surgeons Congenital Heart Surgery Database. Pediatr Cardiol 2019;40:489-96.

34. Landis BJ, Levey A, Levasseur SM, et al. Prenatal diagnosis of congenital heart disease and birth outcomes. Pediatr Cardiol 2013;34:597-605.

35. Laas E, Lelong N, Ancel PY, et al. Impact of preterm birth on infant mortality for newborns with congenital heart defects: The EPICARD population-based cohort study. BMC Pediatr 2017;17:124.

36. Laas E, Lelong N, Thieulin AC, et al; EPICARD Study Group. Preterm birth and congenital heart defects: a population-based study. Pediatrics 2012;130:e829-37.

37. Parikh LI, Grantz KL, Iqbal SN, et al. Neonatal outcomes in fetuses with cardiac anomalies and the impact of delivery route. Am J Obstet Gynecol 2017;217:469.e1-469.e12.

38. Mahle WT, Clancy RR, McGaurn SP, et al. Impact of prenatal diagnosis on survival and early neurologic morbidity in neonates with the hypoplastic left heart syndrome. Pediatrics 2001;107:1277-82.

39. Calderon J, Angeard N, Moutier S, et al. Impact of prenatal diagnosis on neurocognitive outcomes in children with transposition of the great arteries. J Pediatr 2012;161:94-8.e1.

40. Bensemlali M, Bajolle F, Laux D, et al. Neonatal management and outcomes of prenatally diagnosed CHDs. Cardiol Young 2017;27:344-53.

41. Kaguelidou F, Fermont L, Boudjemline Y, et al. Foetal echocardiographic assessment of tetralogy of Fallot and post-natal outcome. Eur Heart J 2008;29:1432-8.

42. Hunter LE, Simpson JM. Prenatal screening for structural congenital heart disease. Nat Rev Cardiol 2014;11:323-34.

43. Bensemlali M, Stirnemann J, Le Bidois J, et al. Discordances Between Pre-Natal and Post-Natal Diagnoses of Congenital Heart Diseases and Impact on Care Strategies. J Am Coll Cardiol 2016;68:921-30.

44. Kailin JA, Santos AB, Yilmaz Furtun B, et al. Isolated coarctation of the aorta in the fetus: A diagnostic challenge. Echocardiography 2017;34:1768-75.

45. Mäkikallio K, McElhinney DB, Levine JC, et al. Fetal aortic valve stenosis and the evolution of hypoplastic left heart syndrome: patient selection for fetal intervention. Circulation 2006;113:1401-5.

46. Gardiner HM, Belmar C, Tulzer G, et al. Morphologic and functional predictors of eventual circulation in the fetus with pulmonary atresia or critical pulmonary stenosis with intact septum. J Am Coll Cardiol 2008;51:1299-308.

47. Andrews RE, Tibby SM, Sharland GK, et al. Prediction of outcome of tricuspid valve malformations diagnosed during fetal life. Am J Cardiol 2008;101:1046-50.

48. Tworetzky W, Wilkins-Haug L, Jennings RW, et al. Balloon dilation of severe aortic stenosis in the fetus: Potential for prevention of hypoplastic left heart syndrome: Candidate selection, technique, and results of successful intervention. Circulation 2004;110:2125-31.

49. Tulzer G, Arzt W, Franklin RC, et al. Fetal pulmonary valvuloplasty for critical pulmonary stenosis or atresia with intact septum. Lancet 2002;360:1567-8.

50. Marshall AC, van der Velde ME, Tworetzky W, et al. Creation of an atrial septal defect in utero for fetuses with hypoplastic left heart syndrome and intact or highly restrictive atrial septum. Circulation 2004;110:253-8.

51. Moon-Grady AJ, Morris SA, Belfort M, et al; International Fetal Cardiac Intervention Registry. International Fetal Cardiac Intervention Registry: A Worldwide Collaborative Description and Preliminary Outcomes. J Am Coll Cardiol 2015;66:388-99.

52. Glatz JA, Tabbutt S, Gaynor JW, et al. Hypoplastic left heart syndrome with atrial level restriction in the era of prenatal diagnosis. Ann Thorac Surg 2007;84:1633-8. 
53. Vlahos AP, Lock JE, McElhinney DB, et al. Hypoplastic left heart syndrome with intact or highly restrictive atrial septum: outcome after neonatal transcatheter atrial septostomy. Circulation 2004;109:2326-30.

54. Szwast A, Tian Z, McCann M, et al. Vasoreactive response to maternal hyperoxygenation in the fetus with hypoplastic left heart syndrome. Circ Cardiovasc Imaging 2010;3:172-8.

55. Lara DA, Morris SA, Maskatia SA, et al. Pilot study of chronic maternal hyperoxygenation and effect on aortic and mitral valve annular dimensions in fetuses with left heart hypoplasia. Ultrasound Obstet Gynecol 2016;48:365-72.

56. Zeng S, Zhou J, Peng Q, et al. Sustained maternal hyperoxygenation improves aortic arch dimensions in fetuses with coarctation. Sci Rep 2016;6:39304.

57. Limperopoulos C, Tworetzky W, McElhinney DB, et al. Brain volume and metabolism in fetuses with congenital heart disease: evaluation with quantitative magnetic resonance imaging and spectroscopy. Circulation 2010;121:26-33.

58. Russo CA, Elixhauser A. Hospitalizations for Birth Defects, 2004: Statistical Brief \#24. 2007 Jan. In: Healthcare Cost and Utilization Project (HCUP) Statistical Briefs [Internet]. Rockville (MD): Agency for

Cite this article as: Bonnet D. Impacts of prenatal diagnosis of congenital heart diseases on outcomes. Transl Pediatr 2021;10(8):2241-2249. doi: 10.21037/tp-20-267
Healthcare Research and Quality (US); 2006.

59. Jegatheeswaran A, Oliveira C, Batsos C, et al. Costs of prenatal detection of congenital heart disease. Am J Cardiol 2011;108:1808-14.

60. Sivarajan V, Penny DJ, Filan P, et al. Impact of antenatal diagnosis of hypoplastic left heart syndrome on the clinical presentation and surgical outcomes: the Australian experience. J Paediatr Child Health 2009;45:112-7.

61. Glasheen C, Richardson GA, Fabio A. A systematic review of the effects of postnatal maternal anxiety on children. Arch Womens Ment Health 2010;13:61-74.

62. Kovacevic A, Simmelbauer A, Starystach S, et al. Counseling for Prenatal Congenital Heart DiseaseRecommendations Based on Empirical Assessment of Counseling Success. Front Pediatr 2020;8:26.

63. Calderon J, Willaime M, Lelong N, et al; EPICARD study group. Population-based study of cognitive outcomes in congenital heart defects. Arch Dis Child 2018;103:49-56.

64. McCusker CG, Doherty NN, Molloy B, et al. A controlled trial of early interventions to promote maternal adjustment and development in infants born with severe congenital heart disease. Child Care Health Dev 2010;36:110-7. 